\title{
Neuropsicologia transcultural: grupo indígena guarani
}

\author{
Vivian Maria Andrade \\ Universidade Federal de Sergipe \\ Orlando Francisco Amodeo Bueno \\ Universidade Federal de São Paulo
}

\begin{abstract}
Resumo
Para investigar a influência da cultura sobre o desempenho cognitivo foram estudados processos intelectuais em indivíduos de populações etnicamente diferentes. Avaliamos 12 índios e 12 pessoas não indígenas, ambos os grupos constituídos por moradores da periferia de São Paulo, pareados de acordo com idade e nível educacional. Os seguintes testes foram utilizados: Dígitos, Blocos de Corsi, Desenho com Cubos e Nomeação de Figuras. A memória verbal imediata e tardia foi avaliada por meio de estórias relacionadas ao contexto ecológico de ambos os grupos, e a memória visual, pela apresentação e recuperação de figuras. Os resultados quantitativos não demonstraram diferenças significativas entre os grupos, porém, houve uma tendência estatística dos índios mostrarem maior domínio das tarefas visuais e motoras, e os não índios das tarefas verbais. Em conclusão, é possível que o grupo indígena use a cognição de forma mais concreta e intuitiva, em função do estilo peculiar de vida, das habilidades desenvolvidas, associado à baixa escolaridade.
\end{abstract}

Palavras-chave: neuropsicologia transcultural; cognição; índio guarani

\begin{abstract}
Cross culture neuropsychology: Guarany indian group. Intellectual processes were investigated in two different populations to study the influence of culture in cognitive performance. Twelve people of an indian population of the Guarany ethnic nation were compared to 12 people ("non-indians") paired according to age and education level, both groups residing in the periphery of the city of São Paulo. The following tests were used: Digit Span; Corsi Block-Tapping Test; Block Design and Naming Figure Test. The immediate and delayed verbal memory was assessed through a short story-task with a specific ecological context and the visual memory through animal figures retrieval. No statistical differences were observed between the two groups, but a statistic tendency was observed in the sense of the indigenous group apparently encountering more facility in visual and motors tasks and the "non-indians" in verbal tasks. The results suggest that the indigenous group used culturally influenced strategies to solve problems and to acquire information, and a more intuitive and concrete utilization of cognition, in conjunction with their own life style as well as poor education.
\end{abstract}

Keywords: crossculture neuropsychology; cognition; guarany indian

$\mathrm{E}$ $\mathrm{m}$ linhas gerais, a neuropsicologia é uma neurociência que avalia os efeitos de lesões cerebrais sobre o intelecto, a emoção e o comportamento (Conselho Federal de Psicologia, 2004); detecta as funções intactas e aquelas comprometidas em decorrência da lesão, e planeja estratégias para reabilitar o indivíduo (Wilson, 1999). Mais abrangente, a neuropsicologia tem ampliado sua área de atuação e incluído estudos que investigam a influência dos aspectos sócio-culturais sobre a cognição. A neuropsicologia transcultural enfatiza a necessidade de personalizar instrumentos de medidas utilizados na avaliação neuropsicológica nas diversas e distintas populações (Ostrosky-Solis, Ardila, \& Rosselli, 1998). Subjacente, discute, por exemplo, que a diferença cognitiva existente entre os vários grupos pode ser mais por influência cultural do que biologicamente determinada (Ardila, Ostrosky-Solis, Rosseli, \& Gómez, 2000; Puente \& Salazar, 1998), e que o modo utilizado pelo indivíduo para resolver problemas também pode sofrer influência cultural (Puente \& Salazar, 1998).

De acordo com teorias que fundamentam a neuropsicologia transcultural, o padrão cognitivo pode ser diretamente influenciado por variáveis relativas aos usos e costumes dos grupos sociais, por exemplo, as condições do habitat, o modo empregado para gerir a subsistência - fatores ecológicos (Vygotsky, Luria \& Leontiev, 1994), os anos de educação e o status social e econômico (Luria, 1994; Vygotsky, 1978). Mas, por outro lado, dependendo da escolha da tarefa e dos determinantes subjacentes à avaliação cognitiva, os resultados podem subestimar a habilidade psicomotora e a capacidade 
intelectual do indivíduo avaliado (Puente \& Salazar, 1998).

Em nosso estudo, tivemos como objetivos principais, investigar a cognição de indígenas aculturados e discutir a influência de variáveis relativas à cultura sobre o escore e sobre o modo de execução dos testes aplicados em indivíduos de etnias diferentes.

\section{Materiais e métodos}

\section{Casuística}

Foram avaliados dois grupos, cada um composto por doze indivíduos, um deles constituído por índios guarani, e o outro por pessoas da mesma idade e escolaridade, mas de cultura diferente (não-índios). Todos os indígenas residiam na Reserva da Barragem - periferia da cidade de São Paulo; os não-índios também residiam nos arrabaldes da cidade.

Os seguintes critérios de inclusão foram utilizados para compor o grupo experimental: ser índio, residir e trabalhar na aldeia, ter escolaridade baixa ou nula (de zero a dois anos de estudos), idade entre 20 e 40 anos, falar português, além da língua nativa deles, o idioma guarani; não fazer uso de drogas de forma abusiva e não ter problema de saúde capaz de influenciar nos resultados da pesquisa (doença psiquiátrica e neurológica, histórico de traumatismo craniencefálico e convulsão).

O grupo de não-índios foi escolhido como parâmetro, tanto quantitativo (para comparar o escore de cada tarefa), quanto qualitativo (para observar o modo de execução das atividades). Os critérios de inclusão neste grupo foram os seguintes: residir na periferia da cidade de São Paulo, mas fora da aldeia; pertencer à classe $\mathrm{D}$ ou $\mathrm{E}$; ser analfabeto ou ter baixa escolaridade; não fazer uso de drogas de forma abusiva e não ter problema de saúde capaz de influenciar no resultado do estudo. A designação da classe social foi observada por meio de vários dados da entrevista, (sobre a profissão, a ocupação, a localização da moradia, por exemplo).

Todos os voluntários consentiram em participar do estudo sem receber valor em espécie. O projeto de pesquisa foi avaliado e aprovado pelo Comitê de Ética em Pesquisa da Universidade Federal de São Paulo (Escola Paulista de Medicina).

\section{Material}

A avaliação cognitiva dos vinte e quatro participantes utilizou os instrumentos descritos a seguir.

Dígitos, Span atencional verbal. Neste teste foi solicitada a repetição de uma seqüência numérica crescente (inferior a uma dezena) na ordem direta (OD). Na segunda parte, a seqüência ouvida foi repetida pelo sujeito na ordem inversa (do último para o primeiro dígito - OI). Esta atividade avaliou a capacidade para manter a atenção auditiva (OD) e para executar tarefas cognitivas verbais simultâneas (OI) (Nascimento, 2000).

Blocos de Corsi, Span atencional visual. Nesta tarefa o voluntário tocou em cubos fixados e dispostos irregularmente em um tabuleiro de madeira na seqüência previamente indicada pelo aplicador (seqüência crescente, apresentada de dois a nove cubos por vez). O escore resultou da capacidade para manter a atenção visuoespacial na (OD) e na (OI) (Lezak, 1995).

Memória visual imediata, tardia e de reconhecimento. Doze figuras de animais (28 X $22 \mathrm{~cm})$, coloridas, foram apresentadas uma a uma (ver Figura 1), com a finalidade de nomeação e recordação de figura. Cada figura foi nomeada pelo sujeito, retirada de sua vista e recordada livremente ao final da apresentação (evocação imediata). Trinta minutos após a apresentação inicial, seguiu-se nova evocação (evocação tardia). Para o teste de reconhecimento foram apresentadas algumas figuras novas e outras já vistas. O instrumento foi adaptado do Teste ABC (Lourenço Filho, 1952).

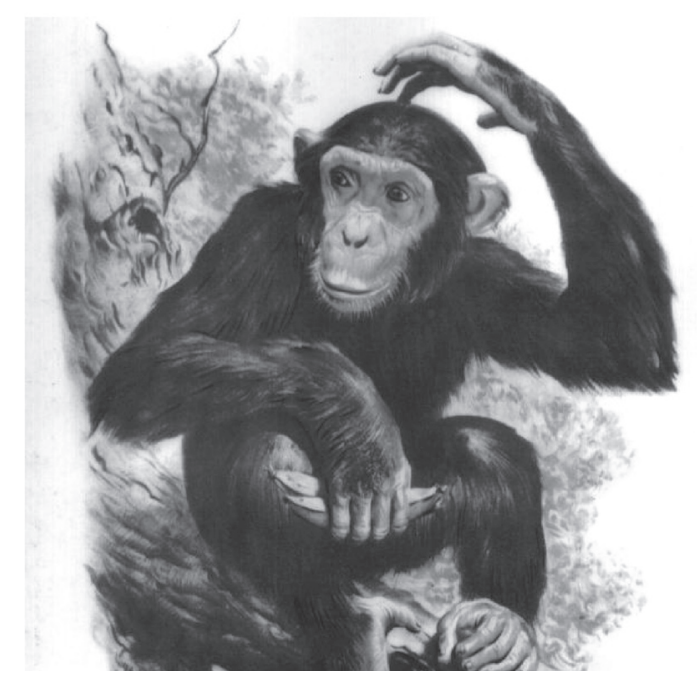

Figura 1. Exemplo de imagem usada no teste de nomeação e recordação de figura.

Nomeação. Figuras de animais.

Memória verbal imediata e tardia. Apresentação da estória A do teste Memória Lógica (Wechsler, 1987), com 25 unidades para os não-índios; e de outra estória (com começo, meio e fim) para o grupo de índios, elaborada pela equipe, em conjunto com estudantes índios residentes na aldeia, e testada previamente entre eles.

Um dia... / bem, já era tardinha,/ Cláudio/ estava sentado em uma pedra/ observando a floresta/ e o barulho que vinha de lá./ Ele falou para mim:/ "Osmar,/ vamos caçar?"/ Daí nós fomos./ Um passarinho/ estava em seu ninho /alimentando os filhotes,/ o ninho estava em uma árvore/ enorme./ Cláudio/ ficou olhando e disse: "é tão bonita / a natureza /e os animais que vivem nela,/ eu queria ser um pássaro/ para poder voar / livre pela floresta".

Desenho com Cubos, habilidade vísuo-construtiva. A tarefa consistiu em passar um modelo bidimensional para um tridimensional; teve como objetivo avaliar as habilidades vísuo-construtivas e a capacidade de resolução de problemas em situação não-verbal (Nascimento, 2000). 


\section{Procedimento}

Ao longo de 36 meses de contatos e de visitas aos indígenas, a escolha de tarefas levando em conta os aspectos ecológicos e o idioma foram as barreiras mais difíceis de serem transpostas. $\mathrm{Na}$ primeira fase, algumas metas foram traçadas: estabelecer contato com o maior número possível de moradores da reserva indígena (trinta índios adultos foram entrevistados); observar o comportamento e conhecer aspectos gerais da cultura guarani (para adquirir alguma familiaridade com as situações do cotidiano indígena e permitir que se familiarizassem com a presença dos pesquisadores). Na segunda fase, realizamos entrevistas semifechadas de acordo com sexo, idade e escolaridade. Aplicamos o conjunto de testes citados e o Teste de Recordação Livre de Palavras em português e em guarani, quando um vínculo entre índios e pesquisadores já havia sido estabelecido.

\section{Análise dos dados}

As técnicas de obtenção de informação utilizadas neste estudo foram: de observação (em que se registrou comportamentos produzidos no contexto ambiental dos índios), e de descrição etnográfica (em que ocorreu a observação participante por meio da interação presente nas várias visitas realizadas à reserva). As informações obtidas foram analisadas utilizando-se estratégias qualitativas. Os dados relativos à técnica neuropsicológica de avaliação cognitiva foram analisados também estatisticamente. Para a comparação do desempenho nos testes cognitivos foi usado o teste $t$ de Student, após a plotagem das curvas apresentarem distribuição normal em ambos os grupos. As diferenças seriam consideradas significativas se $p \leq 0,05$.

\section{Resultados}

Os resultados do teste $t$ indicaram que os dois grupos foram similares em todas as atividades cognitivas apresentadas, pois não houve diferença significativa entre os escores (Tabela 1).

Tabela 1

Avaliação neuropsicológica

\begin{tabular}{lccrcc}
\hline \multirow{2}{*}{ Testes } & \multicolumn{2}{c}{ Média \pm Desvio-padrão } & \multirow{2}{*}{$t$} & \multirow{2}{*}{$p$} \\
\cline { 2 - 3 } & Controle & Índios & & \\
\hline Ordem direta verbal & $4,7 \pm 1,4$ & $3,9 \pm 1,2$ & & 1,475 & 0,15 \\
Ordem inversa verbal & $2,4 \pm 0,5$ & $2,6 \pm 1,0$ & & $-0,650$ & 0,51 \\
Ordem direta visual & $3,6 \pm 1,4$ & $4,6 \pm 1,8$ & & $-1,611$ & 0,12 \\
Ordem inversa visual & $2,9 \pm 1,0$ & $3,5 \pm 1,0$ & $-1,185$ & 0,25 \\
Cubos & $5,7 \pm 5,0$ & $6,6 \pm 5,2$ & 0,399 & 0,69 \\
Nomeação & $9,6 \pm 2,4$ & $9,6 \pm 1,5$ & 0 & 1,00 \\
Memória visual imediata & $7,6 \pm 2,1$ & $8,8 \pm 1,5$ & $-1,500$ & 0,14 \\
Memória visual tardia & $6,9 \pm 2,7$ & $9,0 \pm 1,1$ & $-1,900$ & 0,06 \\
Memória verbal imediata & $6,0 \pm 3,9$ & $5,1 \pm 2,5$ & & 0,600 & 0,53 \\
Memória verbal tardia & $6,0 \pm 3,9$ & $4,8 \pm 4,9$ & & 0,500 & 0,56 \\
\hline
\end{tabular}

Nota. Não houve diferença estatística entre os grupos.

Ao mesmo tempo, a observação realizada sugere que mais do que a forma de resolver problemas (tarefas vísuo-construtivas), as estratégias para adquirir novas informações parecem ter sido diferentes entre os dois grupos.

Quanto à memorização, por exemplo, pôde-se observar maior facilidade dos índios em relatar as primeiras frases da estória do que as últimas, conforme ilustrado na Tabela 2. $\mathrm{O}$ tipo de evocação mais comumente encontrado entre o grupo indígena pode ser exemplificado pelos relatos de evocação 1 , 2 e 3 . O tipo de evocação do caso 4 (em que aparece o fim da história) teve ocorrência menos freqüente; bem como o caso 5 , que foi o único em que a estória foi recordada por inteiro (embora de maneira sintetizada).

Tabela 2

Exemplos de relatos típicos face à evocação imediata da estória ouvida pelos índios

Caso 1: Um dia, Cláudio estava sentado em cima de uma pedra e disse, vamos caçar?

Caso 2: Um dia, Cláudio estava na floresta, ia caçar.

Caso 3: Cláudio estava sentado num dia de tarde e ouviu um barulho.

Caso 4: Cláudio falou que queria ser um pássaro e voar livremente pela floresta.

Caso 5: Cláudio sentou em cima de uma pedra e observou a floresta. Osmar falou para ele: Vamos caçar? Osmar viu um ninho de pássaro e ele disse que queria ser um pássaro para poder voar. 


\section{Discussão}

Tem sido descrito que variáveis relativas à cultura influenciam o resultado de testes cognitivos (Lefèvre, 1989; Luria, 1994, Puente \& Salazar, 1998). Nosso estudo avaliou um grupo de índios aculturados, utilizando testes comuns a neuropsicologia (Dígitos, Cubos de Corsi e Desenho com Cubos), e personalizados ecologicamente (nomeação de figuras e memorização de uma estória), a fim de analisar o desempenho e o modo de execução das tarefas selecionadas.

Os índios pesquisados residiam na periferia da cidade de São Paulo, às margens da Represa de Guarapiranga, no bairro de Santo Amaro, zona sul da capital. A observação da rotina da aldeia constatou que atualmente eles possuem hábitos diferentes da sua cultura original: assistem televisão, ouvem rádio, jogam futebol organizados em times uniformizados; comem comidas industrializadas e vestem roupas comuns. Por outro lado, além das características físicas, o idioma próprio (guarani), os cânticos, as rezas e os costumes, sustentam ser reconhecidos etnicamente como índios. O estilo de vida também é muito peculiar, vivem em casas de taipa ou madeira praticamente sem móveis; plantam em seus sítios (pequenas roças), pescam na represa, alguns vendem os produtos (fruto da roça, e do artesanato). Não possuem um trabalho convencional, como os não-índios; a maior parte não sai com freqüência da aldeia e nem expressa desejo de sair. Pelo conjunto destas características são considerados índios aculturados. Avaliamos seu funcionamento cognitivo, utilizando como referência teorias e técnicas da neuropsicologia transcultural e discutimos os resultados quantitativos e qualitativos das atividades desempenhadas.

Os resultados do teste $t$ mostraram que os grupos pareados, índios e não-índios, apresentaram resultados similares nas várias funções cognitivas investigadas: capacidade atencional verbal e visuoespacial; nomeação de figuras de animais, memorização verbal de uma estória, memorização e reconhecimento visual das figuras de animais; e habilidades vísuo-construtivas. No entanto, o aumento da amostra pode tornar mais claros, resultados, até o momento, percebidos como uma tendência estatística, a de que os índios possuem maior domínio das atividades vísuo-construtivas e visuais do que das tarefas verbais. Por exemplo, o escore de $p$ para o Span visual (OD) foi de 0,12 e de Memória visual tardia de 0,06 , os resultados mais vantajosos foram para o grupo indígena. Porém, em tarefas verbais, tais como o Span verbal (OD), o valor de $p$ foi de 0,15 e o de Memória verbal tardia de 0,56 em favor do grupo não-indígena. O que nos fez supor que os índios apresentaram maior domínio das atividades que continham elementos visuais (memória visual imediata, Cubos de Corsi), e motores (habilidades vísuo-construtivas, Desenho com Cubos) do que da tarefa verbal de ordem similar (Tabela 1).

Lefèvre (1989) tece uma análise em seu trabalho que suporta, em parte, nossos achados, a de que crianças provenientes de áreas rurais carentes, analfabetas, usam mais constantemente a inteligência prática e o raciocínio espacial do que conceitual; o fazer, o agir, mais do que o mundo das idéias, analítico-cognitivo. O grupo pesquisado em nosso estudo, foi constituído por indivíduos analfabetos ou com até dois anos de escolaridade.

Luria (1994) apresentou relato de experiência parecida, conduzindo uma série de trabalhos de campo sobre o desempenho neuropsicológico de indivíduos residentes em vilarejos e áreas rurais bastante isoladas e pouco desenvolvidas, do Usbequistão e do Quirguistão, na Ásia Central. Observou que os trabalhadores rurais, analfabetos, moradores destas áreas apresentavam respostas menos elaboradas do que as de pessoas que tinham maior escolaridade e outro tipo de trabalho (tarefas mais modernas). As pessoas do primeiro grupo não usavam a mesma lógica para deduções que as do segundo, nem tampouco estabeleciam relações entre os objetos igualmente, ou eram capazes de fácil abstração. Ao darem suas respostas utilizavamse constantemente de suas experiências cotidianas, remetendo estas respostas mais para o que conheciam de fato (raciocínio concreto), do que para abstrações, inferências e hipóteses acerca dos fenômenos (raciocínio dedutivo).

Em nosso estudo, presenciamos situação análoga ao apresentarmos, no protocolo inicial, a mesma história, Memória Lógica A - WMS - R (Wechsler, 1987), para índios e nãoíndios. Observamos que os índios não conseguiam recontar, satisfatoriamente, o conteúdo que tinham acabado de ouvir, o que nos fez supor que por tratar-se de um contexto distante da realidade deles, tornava-se mais difícil memorizar. Deste modo, uma outra história foi elaborada e apresentada, levando em conta o contexto ecológico indígena, ainda que não pudessem utilizar estratégias de repetição para facilitar o processo de aquisição (pois, após ouvirem tinham de repetir a estória imediatamente). Os fatos da nova narrativa permitiam associar, ou estabelecer relações, com experiências da própria vida deles. A mudança parece ter contribuído para que o grupo indígena tivesse mais chance de recordar a nova estória de forma hábil, ainda que, possivelmente, estivessem fazendo uso de recursos cognitivos menos sofisticados.

Outros autores, que também investigaram características cognitivas em população indígena (Dehaene, Izard, Pica, \& Spelke, 2006), sugeriram a existência de um conjunto de intuições presente, naturalmente, em todos os seres humanos. Seriam espontâneas e constituídas, até mesmo na ausência da escolarização. Nesse estudo, eles apontaram o conhecimento de geometria como um exemplo, após investigarem índios isolados da Amazônia em distintas fases do desenvolvimento. Utilizaram atividades que envolviam a compreensão e interpretação de conceitos geométricos básicos: pontos, linhas, paralelas, ângulos retos inseridos em figuras simples; e observaram que os elementos foram utilizados instintiva e naturalmente pelos índios munduruku. As tarefas permitiam destacar que os índios tinham noção de distância, senso de direção, quando tinham que, baseados em mapas geométricos, localizar objetos escondidos. Esses índios não eram aculturados, como os de nosso estudo; era baixa a probabilidade de convivência prévia com populações de outras culturas que pudessem tê-los capacitado nos quesitos avaliados.

Por outro lado, Ostrosky-Solis, Ardila e Rosselli (1998) compararam analfabetos a várias faixas de escolaridade, e constataram que os anos de estudo influenciaram diretamente um conjunto de funções: a linguagem (compreensão e a fluência verbal fonológica), as funções conceituais que envolvem maior grau de abstração (semelhanças, cálculos e seqüências), e as 
habilidades vísuo-construtivas. O parâmetro utilizado foi o desempenho de pessoas da mesma cultura, com os de 1-2 ou 3-4 anos de escolaridade comparados aos sem escolarização. Parece, portanto, que com o aumento da escolaridade - aprendizagem da leitura, da escrita e do cálculo -, o uso da abstração acerca dos fenômenos, ou de inferências, hipóteses e deduções torna-se mais evidente (Ardila et al., 2000; Luria, 1994; Ostrosky-Solis, Ardila, \& Rosselli, 1998). A neuropsicologia, com o apoio da neuroimagem, mostra que a escolaridade promove mudanças na percepção visual, no raciocínio lógico, nas estratégias de memorização, na resolução de problemas, entre outras capacidades e habilidades (Ardila et al., 2000). Resultados de outros pesquisadores (Halpern et al., 2000; Lichtig et al., 2001), que igualmente manejam variáveis sócio-econômicas, confirmam que o desenvolvimento psicomotor, ou mesmo o desenvolvimento global da criança (Nunes, 2001), sofre influência até mesmo do tipo de nutrição recebida.

Segundo Rego (1999), Vygotsky admitiu a existência de uma base biológica para o funcionamento dos processos psicológicos básicos (ações reflexas, reações automáticas e associações simples) no início da vida, anterior ao efeito cultural sobre o desenvolvimento. Para o autor, mecanismos intencionais, voluntários - as funções psicológicas superiores: raciocínio, memória declarativa, planejamento e organização, por exemplo - se desenvolveriam gradativamente a partir da interação consciente da criança com seu próprio contexto sóciocultural, tornando estes parte constitutiva da sua natureza. Cruz e Landeira-Fernandez (2007) lembram que a plasticidade cerebral é exatamente a habilidade de o cérebro reorganizar suas vias neurais com base, principalmente, nas experiências ao longo da vida, modificando-se estrutural e funcionalmente.

Outra questão refere-se ao cuidado com a escolha do instrumento a ser utilizado na avaliação neuropsicológica e, também, com os parâmetros de comparação estabelecidos. Puente e Salazar (1998) sublinharam o fato de que as diferenças no desempenho cognitivo de pessoas pertencentes a raças e grupos étnicos distintos precisam ser avaliadas com rigor metodológico para que não ocorra um viés nos resultados em função de variáveis não relacionadas ao intelecto. Dados obtidos após aplicação das baterias Wechsler em crianças descendentes de mexicanos, nascidos nos Estados Unidos, indicaram escores menores por parte das crianças ticanas. Porém, o teste é originalmente americano, idealizado e normatizado segundo amostras daquela população; e, muitas vezes, aplicado também por psicólogo americano, favorecendo ainda outros vieses.

Ostrosky-Solis, Ardila e Rosselli, (1998) relataram que o conteúdo dos testes utilizados em sua amostra foi específico para aquela cultura, a versão em espanhol da bateria NEUROPSI normatizada e padronizada. Neste caso, de maneira diferente do nosso trabalho, os autores utilizaram a cópia de figuras com lápis e papel.

Atentos a estas questões, escolhemos testes simples (verbais e psicomotores), sem uso de lápis e de papel. A maior parte das figuras de animais selecionadas tinha a ver com o contexto ecológico indígena, e as histórias, com o contexto sócio-cultural de ambos os grupos. Os indígenas estavam familiarizados com a presença da equipe na aldeia e manifestavam interesse em participar das atividades (sempre nos receberam bem, mostrando curiosidade e bom humor). Embora os dois grupos se mostrassem motivados e engajados na execução das tarefas, as palavras e atitudes dos índios indicavam que estavam se divertindo com a situação de teste, sem se importar tanto com seus erros e dificuldades. Para os não-índios, os erros e as dificuldades eram mais fortemente percebidos como fracasso, despertando sentimentos de menos valia e desapontamento, verbalizados para o aplicador.

Em resumo, parece que a cultura - o estilo de vida no qual o indivíduo está inserido, o status sócio-econômico, os anos de escolaridade, o habitat - mais do que a etnia, influencia a cognição humana. Supõe-se que estes fatores culturais possam favorecer a modelagem do substrato anatômico por meio da citoarquitetura cerebral, que proporciona suporte a constituição de estratégias de memória, ao uso das funções verbais e das habilidades vísuo-espaciais e vísuo-construtivas, bem como, significado subjetivo às experiências emocionais. Some-se, ainda, o fato de que os instrumentos utilizados para a avaliação neuropsicológica devem ser adequados para o contexto ecológico dos indivíduos investigados.

Como os resultados quantitativos não apontaram diferenças entre os grupos, sugerimos que outras investigações sejam levadas adiante, com amostras maiores, para dar continuidade às idéias aqui investigadas e discutidas.

\section{Agradecimentos}

Agrademos a Antonio Puente (University of North Carolina at Wilmington, EUA), Miguel Perez (Universidad de Granada, Espanha), Eduardo Navarro (Universidade de São Paulo), Sergio Tufik (Universidade Federal de São Paulo), Associação Fundo de Incentivo a Psicofarmacologia (AFIP), CAPES, CNPq e as estagiárias Maria da Glória S. Vieira, Adriana Souza e Shirley A. Andrade.

\section{Referências}

Ardila, A., Ostrosky-Solis, F., Rosseli, M., \& Gómez, C. (2000). Age-related cognitive decline during normal aging. Archives of Clinical Neuropsychology, 15(6), 495-513.

Conselho Federal de Psicologia (2004). Resolução Noo 002 de 03 de Março de 2004. Obtido em 08 de setembro de 2005, de http://www.pol.org.br/atualidades/matéria.cfm?id.área $=658$.

Cruz, A. P. M., \& Landeira-Fernandez, J. (2007). Por uma psicologia baseada em um cérebro em transformação. In J. Landeira-Fernandez \& M. T. S. Silva (Orgs.), Intersecções entre psicologia e neurociências (pp. 1-15). Rio de Janeiro: MedBook.

Dehaene, S., Izard, V., Pica P., \& Spelke, E. (2006). Core knowledge of geometry in an Amazonian indigene group. Science, 311, 381-384.

Halpern, R., Giugliani E. R. J., Victora, C. G., Barros F. C., \& Horta, B. L. (2000). Fatores de risco para suspeita de atraso no desenvolvimento neuropsicomotor aos 12 meses de vida. Jornal de Pediatria, 76(6), 421-428.

Lefèvre, B. H. (1989). Neuropsicologia infantil. São Paulo: Savier.

Lezak, M. D. (1995). Neuropsychological Assessment (3 ${ }^{\mathrm{a}}$ ed). Nova York: Oxford University Press. 
Lichtig, I., Monteiro, S. R. G., Couto, M. I. V., Haro, F. M. B., Campos, M. S. C., Vaz, F., et al. (2001). Avaliação do comportamento auditivo e neuropsicomotor em lactantes de baixo peso ao nascimento. Revista da Associação Médica Brasileira, 47(1), 52-58.

Lourenço Filho, M. B. (1952). Teste ABC. São Paulo: Melhoramentos.

Luria, A. R. (1994). Desenvolvimento cognitivo. São Paulo: Ícone.

Nascimento, E. (2000). Escala de Inteligência de Wechsler - III. São Paulo: Casa do Psicólogo.

Nunes, M. L. (2001). Clinical aspects of an under diagnosed disease. Jornal de Pediatria, 77, 29-34.

Ostrosky-Solis, F. Ardila, A., \& Rosselli, M. (1998). Neuropsychological test performance in illiterate subjects. Archives of Clinical Neuropsychology, 13(7), 645-660.
Puente, A. E., \& Salazar, G. D. (1998). Assessment of minority and culturally diverse children. In A. Prifitera \& D. H. Saklofske (Orgs.), WISC-III clinical use and interpretation (pp. 227-248). San Diego: Academic.

Rego, T. C. (1999). Vygotsky: uma perspectiva histórico-cultural da educação. Petrópolis: Vozes.

Vygotsky, L. (1978). Mind in Society. Cambridge, Massachusetts: Harvard University Press.

Vygotsky, L., Luria, A. R., \& Leontiev, N. A. (1994). Linguagem, desenvolvimento, e aprendizagem. São Paulo: Ícone.

Wechsler, D. (1987). Wechsler Memory Scale revised manual. San Antonio: Psychological Corporation.

Wilson, B. A. (1999). Case studies in neuropsychological rehabilitation. Oxford: Oxford University Press.

Vivian Maria Andrade, doutora em psicobiologia pela Universidade Federal de São Paulo, é neuropsicóloga no Hospital Universitário e docente na Universidade Federal de Sergipe. Endereço para correspondência: Universidade Federal de Sergipe; Departamento de Fisiologia, sala 11; Av. Marechal Rondon S/N (Rosa Elze); São Cristóvão, SE; CEP: 49100.000. Tel.: (79) 3212-6645. Fax: (79) 3212-64.74 Email: viviand@ psicobio.epm.br

Orlando Francisco Amodeo Bueno, doutor em psicobiologia pela Universidade Federal de São Paulo, é professor na mesma instituição. E-mail: ofabueno@psicobio.epm.br 